SHS Web of Conferences 7, 01005 (2014)

DOI: $10.1051 /$ shsconf / 20140701005

C) Owned by the authors, published by EDP Sciences, 2014

\title{
Analysis of China Fiscal System for Deepwater Oil and Gas Development under Uncertainty
}

\author{
Liu Mingming, Wang Zhen ${ }^{\mathrm{a}}$, Pan Yanni \\ Academy of Chinese Energy Strategy, China University of Petroleum-Beijing, 102249 Beijing, China
}

\begin{abstract}
World deepwater is famous for its rich oil and gas reserves, and has become an important source of global oil and gas supply, with a rising investment which will be over the shallow water counterparts in the next few years, as well as an expansion of oil and gas output. The 'Deepwater Golden Triangle' of the North American Gulf of Mexico, Brazil and West Africa has been leading the most exploration, development and investment activities in the world, and their experience on fiscal system during different development stages has great reference value other than advanced technologies. Under the assumptions of uncertain oil price and producing cost, this paper analyzed China fiscal system for deepwater oil and gas development, modeled the free natural resource tax, uplifting the threshold of special oil levy, and other scenarios, and compared their results on contractor's net presented value, internal return rate and present index. Based on net present value, internal return rate, profitability index, as well as the domestic fiscal policies, this paper found that Special Oil Levy levied only on profit oil and the cancel of government share oil would have the most significant incentives, while lower the income tax rate to $15 \%$, raising the threshold price at which the Special Oil Levy payable by 15 $\$ /$ bbl and zero Value-added tax have much higher feasibility.
\end{abstract}

Keywords. deepwater oil and gas development; South China Sea; fiscal system; special oil levy

The recoverable reserves of global offshore oil are about 135 billion tons, while those of natural gas are about 1.4 million cubic meters which respectively account for $51 \%$ and $42 \%$ of those on land. While among them, about $30 \%$ are deepwater resources [1]. Since the drill of the first deepwater exploration well in 1975, rich reserves and bright development prospect of deepwater oil and gas resources have attracted more than 60 countries to explore and develop in the deep sea. Investment on deepwater oil and gas development has shown exponential growth and will exceed investment on shallow water in the next few years. Deepwater oil and gas development technology has continuously achieved breakthroughs, and depth of drilling operation has reached 3000 meters. The proportion of deepwater oil and gas production keeps on increasing which will jump from $7 \%$ of global oil and gas production to $13 \%$ in 2035. In addition to traditional "Deepwater Golden Triangle" district in Gulf of Mexico, Brazil and Western Africa, Australia, Southeast Asia and many other new focal areas also show bright potentials. At present, production of deepwater oil and gas in Gulf of Mexico and Brazil has exceeded that of shallow water areas. Petroleum production in Gulf of Mexico even accounts for

\footnotetext{
${ }^{\text {a }}$ Corresponding author: wangzhen@cup.edu.cn
}

This is an Open Access article distributed under the terms of the Creative Commons Attribution License 4.0, which permits unrestricted use, distribution, and reproduction in any medium, provided the original work is properly cited. 
about $80 \%$ of that in the whole district. Marine oil and gas exploration inevitably comes to deepwater level.

It is undeniable that increasing maturity of deepwater oil and gas exploration technology and continuous jumping of oil price are key factors contributing to global oil and gas exploration in deep sea. At the same time, we cannot ignore policy of financial support provided by every country. Taking America for example, to improve deepwater oil and gas development, American government came up with $<$ DWRRA $>$ in September, 1995. Then the production of deepwater oil and gas in Gulf of Mexico increased geometrically in 5 years, the production of crude oil which exceeded 1000 feet increased from 55.20 million barrels in 1995 to 0.27 barrels in 2000; while the proportion of the whole region increased from $16 \%$ to $52 \%$. The output of natural gas increased from 184.6 billion cubic foot to 998.9 billion cubic foot, and the proportion increased from 3.8\% to $20 \%$ [2]. The policy of low income taxes in other countries, such as Nigeria, has also propelled the development of deepwater oil and gas resources.

At present, as we are at the beginning of deepwater oil and gas development, there is huge gap of technology and scale between Golden Triangle District and our country. This directly leads to incomprehensive use of deepwater resource in South China Sea. However, our county's only decrease resources tax by $30 \%$ for oil and gas fields which are over 300 meters. Considering the rate of resources tax is $5 \%$, this kind of preferential policy cannot solve the problem. Aiming at the construction of production sharing contract of current foreign cooperation in our country is based on uncertainty, and referring to several deepwater preferential policies in foreign countries, this paper aims to analysis the finance and taxation system of China deepwater oil and gas development and hope to provide advice to reform of finance and taxation policies on deepwater oil and gas development in our country.

\section{Key finance and tax clauses of china's offshore oil and gas contracts}

At present, China's foreign cooperation adopts finance and taxation system based on production sharing contract which includes exploration period, development period and production period. Generally, China National Offshore Oil Corporation, as government's representative, can at most obtain $51 \%$ of interests and rights for commercial discovery of offshore oil and gas. Contractors should cover all the expenses for exploration and bear all the risks; while expenses for development should be provide in accord with ratio of every contractors share ${ }^{[3]}$. What's more, contractors should totally pay 1 million dollars as advance deposit in 3 times, and should pay China about 50,000 dollars as training expense every year. The allocation of output between country, CNOOC and contractors in the process of production shows in Figure 1: 


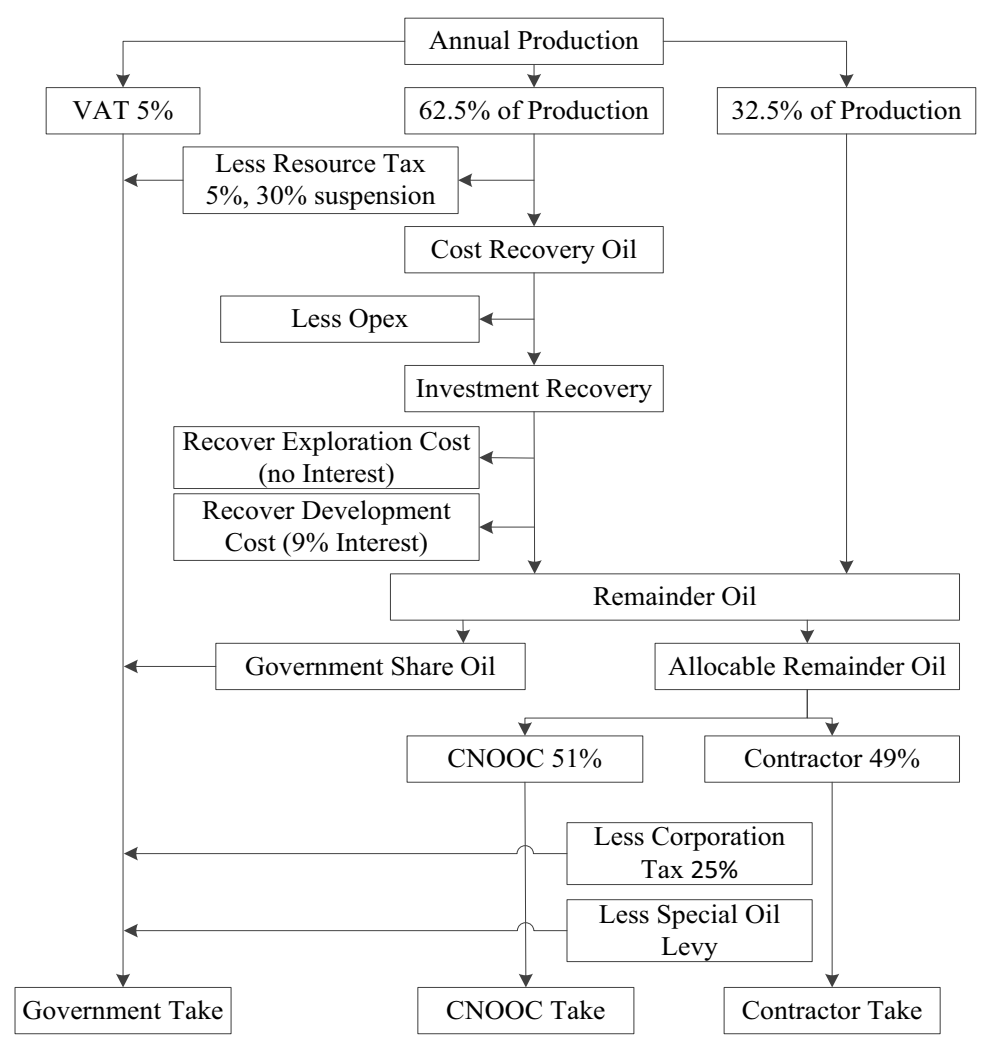

Figure 1. Output allocation process of China's deepwater oil and gas product based on sharecropping contracts

\subsection{Value-added tax}

According to Chinese government regulations, contractors should firstly pay their value-added taxes in kind, that is $5 \%$ of the annual crude oil production.

\subsection{Resources tax}

In September, 2011, the State Council of China has passed the decision on revising the "Resources Tax Provisional Regulations of People's Republic of China" which adds in ad valorem in levy of resources tax, changes levy of resources tax on crude oil and natural gas from quantity-based collection to ad valorem and correspondingly increases the tax burden level of crude oil and natural gas, the tax rate is $5 \%$ to $10 \%$ (At present, $5 \%$ as it is provisionally decided), at the same time, unifies the tax system of oil and gas resources in foreign and domestic-funded enterprises, cancels mining royalty of Chinese-foreign cooperation or offshore self-run oil and gas fields and levies resources tax instead.

On November 15, 2011, as the Ministry of Finance and State Administration of Taxation pointed in "Notice on Relevant Problems in Resources Tax Reform of Crude Oil and Natural Gas", we provide a $30 \%$ discount for resources tax of deepwater oil and gas which is over 300 meters (not include) under the sea.

\subsection{Cost recovery}

But after the reform of resources tax, China cancels mining royalty and changes to levy resources tax with undefined upper limit of cost recovery oil. Thus, we can know, cost recovery oil is the remaining 
part which $62.5 \%$ of annual total output of crude oil deducts resources tax, mineral resources compensation fees. We call the remaining part of cost recovery oil which deducts operation cost as "investment recovery oil", which is used for contractors' cost of exploration, development and interests. As for costs which are not recycled, it allows to carry down to the next period until all of them are recycled. At the same time, Chinese government asks for $9 \%$ interests from annual development expenses which are not recycled. As for cost recovery oil which is unused, it will automatically reckon in profit oil.

\subsection{Profit sharing}

After pay VAT, mining royalty and cost recovery, the remaining part of annual total output of crude oil is "Remainder Oil" which will be divided into "Chinese Share Oil" and "Allocable Profit Oil" two parts. The annual output of allocable profit oil in every oil field should equal to the result of the output of remainder oil this year multiply by the share rate which is suitable for contract oil field (X). And the share rate of each oil field (X) should be confirmed by the successive incremental tiers of annual total output of crude oil. As it shows in Table 1:

Table 1. Profit sharing ratio of China's marine products based on sharecropping contracts.

\begin{tabular}{ccc}
\hline Annual Output (Megaton) & $\begin{array}{c}\text { Annual Output } \\
\text { (Thousand barrels/Day) }\end{array}$ & Allocable Profit Oil (\%) \\
\hline$<0.5$ & $<10$ & 100 \\
$0.5-1.0$ & $10-20$ & 100 \\
$1.0-2.0$ & $20-40$ & 95 \\
$2.0-3.0$ & $40-60$ & 90 \\
$3.0-5.0$ & $60-100$ & 85 \\
$5.0-7.5$ & $100-150$ & 80 \\
$7.5-10.0$ & $150-200$ & 70 \\
$>10.0$ & $>200$ & 60 \\
\hline
\end{tabular}

Allocable Profit Oil, which is annually produced from oil fields, will be shared between state corporations and other contractors, according to their investment proportion in these oil fields.

\subsection{Income tax}

After contractors obtain cost oil and profit oil, they should pay income taxes for the remaining parts which exclude various expend and special gain levy. The tax rate is $25 \%$, and the cost of capital will carry on straight-line depreciation based on 8 years.

\subsection{Special gain levy}

China introduced special gain levy in 2006, and announced that contractors should pay special gain levy for cost oil and profit oil they have gained, when the oil price is over 40 dollars per barrel. And Chinese government has raised the tax threshold to 55 dollars per barrel. As it explicitly shows in Table 2: 
Table 2. Special gain levy ratio in product sharing of China's marine product.

\begin{tabular}{cc}
\hline Oil Price (Dollar/Barrel) & Ratio \\
\hline $55-60$ & $20 \%$ \\
$60-65$ & $25 \%$ \\
$65-70$ & $30 \%$ \\
$70-75$ & $35 \%$ \\
$>75$ & $40 \%$ \\
\hline
\end{tabular}

In conclusion, contractors should pay value-added taxes, mining royalty, income taxes and special gain levy, and bear all expenses for exploration, development cost which corresponds to interests they gain, as well as operating cost. At the same time, they earn net margin which exclude all these expenses from sales revenue. Chinese government then gain the value-added taxes, mining royalty, share oil, income taxes and special gain levy which paid by investment.

\section{Uncertainty of oil price and its realization}

In international petroleum market, factors which have an influence on petroleum price not only include the basic supply-demand relationship, but also many others, such as speculation in petroleum futures market. These factors interweave with each other and are hard to be accurately quantized, which contribute to uncertainty in the forecast of petroleum price. The models which are used to describe the random process of petroleum price mainly include GBM (Geometric Brownian Motion), MRP (Mean-Reverting Process) and so on. [4-6] According to statistics of petroleum price in 127 years, Pindyck points out that the petroleum price is the most in accord with MRP. Thus, this paper chooses to describe the uncertainty of petroleum price based on MRP.

\subsection{Mean-reverting process}

Mean Reversion Process refers to as the process of exorbitant prices or low price reverting to the mean. If an underlying asset obeys MRP, thus:

$$
\mathrm{d} P=\eta P(\bar{P}-P) \mathrm{d} t+\sigma P \mathrm{~d} z
$$

In the equation above, $\eta$ represents the speed of mean reverting of assets price, $\bar{P}$ refers to as the mean of long-term reverting of underlying assets. As equation (1) shows, the price of underlying assets may be influenced by a kind of restoring force and flow to long-term equilibrium price.

\subsection{The realization of mean-reverting process}

To simplify the model, we adopt Schwartz's method and suppose oil price P obeys MRP [4]:

$$
d P=\eta P(m-\ln P) d t+\sigma P d z
$$

In the equation above, $m$ represent the logarithm of long-term reverting mean of oil price.

According to Ito's Lemma, if variable $\mathrm{x}$ obeys the process of Ito, thus, function $\mathrm{G}$ of variable $\mathrm{x}$ and $t$ will act up to the following process:

$$
d G=\left(\frac{\partial G}{\partial x} a+\frac{\partial G}{\partial t}+\frac{1}{2} \frac{\partial^{2} G}{\partial x^{2}} b^{2}\right) d t+\frac{\partial G}{\partial x} b d z
$$

In the equation above, $d z$ represents an increment on standard Wiener process. 
Put $x=\ln P$ into equation (3), we can find out:

$$
\mathrm{d} x=\eta^{*}\left(m^{*}-x\right) \mathrm{d} t+\sigma \mathrm{d} z
$$

In the equation, $\eta^{*}=\eta, m^{*}=m-\sigma^{2} /(2 \eta)$.

$x$ obeys logarithmic normal distribution, thus its expectation and variance are:

$$
\begin{gathered}
E(x(t))=m^{*}+\left(x(0)-m^{*}\right) \exp (-\eta t)=x(0) \exp (-\eta t)+m^{*}(1-\exp (-\eta t)) \\
\operatorname{VAR}(x(t))=[1-\exp (-2 \eta t)] \sigma^{2} /(2 \eta)
\end{gathered}
$$

In the equation (4), the mean value of $\mathrm{x}$ is the result of weighting between current value $x(0)$ and long-term reverting mean $m^{*}$. With the increasing of $\mathrm{t}, \mathrm{x}$ will more and more approach mean value $m^{*}$, this has clearly shown the process of mean reverting. Otherwise, variance will also gradually converge to $\sigma^{2} /(2 \eta)$ with the increasing of $t$.

By the reverting of AR (1) ${ }^{[4,8]}$, we can find out:

$$
x_{t}-x_{t-1}=m^{*}\left(1-e^{-\eta^{*} \Delta t}\right)+\left(e^{-\eta^{*} \Delta t}-1\right) x_{t-1}+\varepsilon_{t}
$$

In this equation, $\varepsilon_{\mathrm{t}}$ obeys the normal distribution which mean value is 0 and standard deviation is $\sigma_{\mathrm{z}}$. And we can also find out $\sigma_{\varepsilon}^{2}=[1-\exp (-2 \eta)] \sigma^{2} /(2 \eta)$.

To estimate the parameter of mean reverting, we make the reverting process through record oil price:

$$
x_{t}-x_{t-1}=a+b x_{t-1}+\varepsilon_{t}
$$

After we figure out intercept a and slope $b$, then we can find out:

$$
\begin{gathered}
m^{*}=-a / b ; \\
\eta^{*}=-\ln (1+b) ; \\
\sigma=\sigma_{\varepsilon} \sqrt{2 \ln (1+b) /\left((1+b)^{2}-1\right)} ;
\end{gathered}
$$

Based on the price of WTI which EIA formulated during January, 2000 to November, 2013, we can calculate the long-term reverting mean of oil price is 108.05 dollars per barrel, the annual volatility $\sigma$ is 0.30 and the speed of mean reverting $\eta$ is 0.2005 .

After we figure out $\sigma$ and $\eta$, then put them into equation (4) and (5), we can find out the mean value and variance of normal distribution which annual logarithm oil price obeys. Carrying out Monte Cario simulation by @Risk, then it will produce random numbers which obeys normal distribution, and then we can finally figure out the oil price which obeys MRP through conversion.

\section{Comparison between finance and tax clauses}

\subsection{Oil field parameter}

Supposing we construct a deepwater oil project in 2014, and put it into use in 2017 to 2038. In the contract period, we totally invest 0.68 billion dollars in exploration, 28.683 billion dollars in development and produce total 120,961 barrels of crude oil. Supposing the disposal cost is $10 \%$ of expenses for development and count and draw depending on output. 


\subsection{Evaluation parameter}

(1) Production cost of case oil

Supposing the production cost of case oil obeys triangle distribution $(10,15,20)$, that is, the lowest cost of a barrel of case oil is ten dollars, while the highest cost of a barrel of case oil is twenty dollars, but the most possible cost for a barrel of case oil is fifteen dollars.

(2) Others

Supposing the discount rate is $10 \%$, and inflation rate is $2 \%$.

\subsection{What-if scenarios analysis}

This analysis aims to discuss the level of motivation sparked by various kinds of preferential policies for deepwater oil and gas development. Thus, in setting of these scenarios, we refer to preferential policies for taxes on deepwater in America, Brazil, Nigeria and many other countries. Based on current tax system, Scenarios which are set for comparison in this paper include:

(1) Scenario of value-added tax

In addition to baseline scenario, we set a drawback scenario of value-added tax.

(2) Scenario of resources tax

In addition to baseline scenario, we set two kinds of scenarios-halving the resources tax and freeing resources tax.

(3) Scenario of special gain levy

As for special gain levy, in addition to baseline scenario, we raise the tax threshold of special gain levy by fifteen dollars per barrel, only aiming at two kinds of scenarios on levy of profit oil. Table 3 shows the norms of special gain levy after the increase of tax threshold:

Table 3. Special gain levy ratio in product sharing of China's marine product.

\begin{tabular}{cc}
\hline Oil Price (Dollar/Barrel) & Ratio \\
\hline $70-75$ & $20 \%$ \\
$75-80$ & $25 \%$ \\
$80-85$ & $30 \%$ \\
$85-90$ & $35 \%$ \\
$>90$ & $40 \%$ \\
\hline
\end{tabular}

(4) Scenario of profit sharing

In addition to baseline scenario, we set a kind of scenario - canceling Chinese share oil.

(5) Scenario of income tax

In addition to baseline scenario, we set another scenario which income tax rate is $15 \%$.

\subsection{Stimulation frequency}

Monte Cario Simulation randomly choose quantitative value according to the distribution of variables, and we can clearly estimate the income and risks of project by numerous and independent double counting, as well as statistical results of correlation index. In this process, the decision on stimulation times is of great importance. The methods which decide stimulation sample size mainly include practical judgment method, absolute deviation method and relative deviation method [9] [8]. For it is hard to confirm population mean, the author decide to adopt practical judgment method. The change of mean value and variance of net present value with the change of stimulation times shows in figure 2 : 


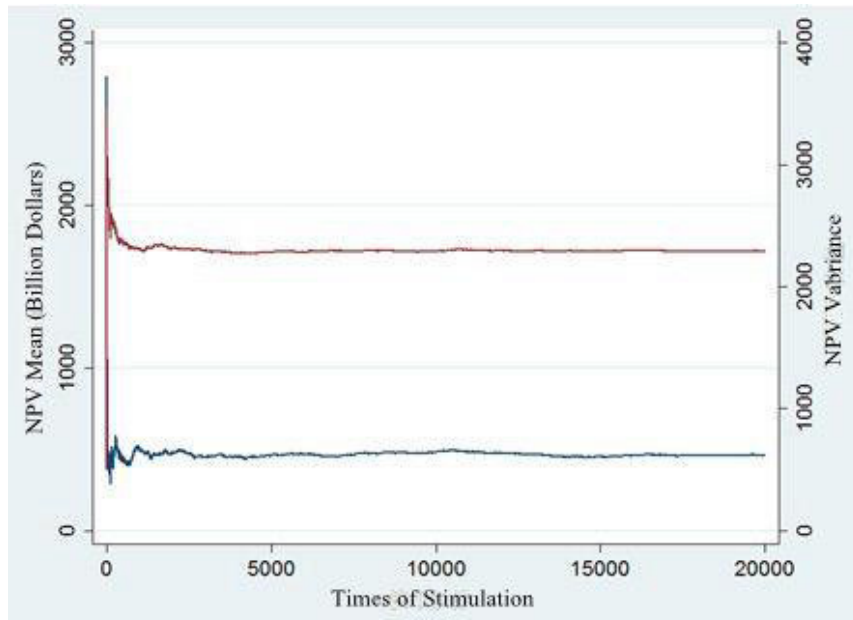

Figure 2. The change of mean value and variance of accumulation sample of net present value with the change of stimulation times

We can figure out in figure 1, when the initial stimulation times decrease, mean value and variance of contractors' net present value are vibrate violently; while with the increase of stimulation times, especially after 15,000 times, both sides gradually reach stability. So, we take 20,000 stimulation times in this paper.

\section{Contract stimulation in different scenarios}

In order to compare contractors' income in different scenarios, we choose three indexes-net present value, internal rate of return (IRR) and investment present index. Net present value shows contractors' investment benefit, IRR reflects contractors' abilities to conquer risks in investment, while investment present index shows contractors' investment efficiency.

\subsection{Stimulation frequency}

In the baseline scenario, that is current financial and taxation system, taking the uncertainty of petroleum price and production cost into consideration, the distribution of net present value which contractors can obtain shows in figure 3 :

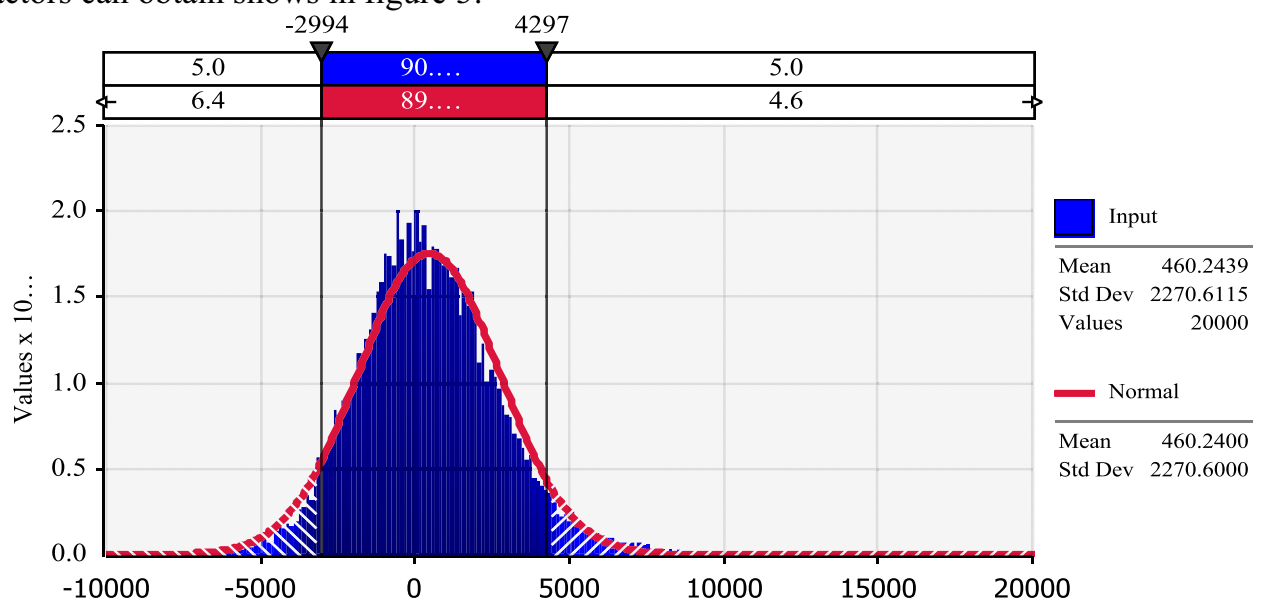

Figure 3. The distribution of contractors' net present value in baseline scenario 
As it shows in figure 9, the mean of contractors' net present value obeys normal distribution which mean is 460.24 and standard deviation is 2270.6 . In addition, the mean of IRR is $10.87 \%$, and investment present value index is 1.01 .

\subsection{Comparison of different scenario}

Based on the baseline scenario, we can figure out different stimulation results in different scenarios through changing key finance and taxation clauses. As it shows in table 4:

Table 4. The comparison of contractors' income in different scenarios.

\begin{tabular}{cccc}
\hline Index for Comparison & $\begin{array}{c}\text { Net Present Value } \\
\text { (Billions of Dollars) }\end{array}$ & IRR & Investment Present Index \\
\hline Baseline Scenario & 4.60 & $10.87 \%$ & 1.010 \\
Drawback of VAT & 9.58 & $12.03 \%$ & 1.041 \\
Halving Resources Tax & 6.56 & $11.33 \%$ & 1.023 \\
Resources Tax Free & 8.58 & $11.04 \%$ & 1.035 \\
Cancelling Share Oil & 11.25 & $12.30 \%$ & 1.050 \\
Special Gain Levy on Profit Oil & 15.75 & $13.52 \%$ & 1.091 \\
The Increase of Tax Threshold of & & & 1.045 \\
Special Gain Levy by 15 dollars & 9.73 & $12.04 \%$ & \\
per barrel & & & 1.054 \\
15\%Income Tax & 10.93 & $12.32 \%$ & \\
\hline
\end{tabular}

In these eight scenarios we show in this paper, taking the uncertainty of oil price and production cost, especially when levying special gain levy for profit oil, that is cancelling levy tax for contractors' cost oil can to the most extent improve contractors' various kinds of income index. Otherwise, we also can receive good result if cancel Chinese share oil in the process of profit allocation. However, the difficulty to implement these policies makes it impossible to put them into use at this phase. While, according to income taxes rate of $15 \%$ which our country designs to encourage investment in west part and development of high-tech enterprises, it's possible to do the same in deepwater oil and gas development. This policy can also widely improve contractors' income indexes, such as raising contractors' net present value from 0.46 billion dollars to 1.093 billion dollars. Even though, raising tax threshold for special gain levy by 15 dollars per barrel and drawback of VAT have less encouragement for contractors, they have more feasibility to be put into use in current phase and we also have experience in implementing the drawback of VAT.

After further comparison, under the current policy which current rate of resources tax is $5 \%$ and decrease $30 \%$ in the depth of over 300 meters, as for the preference of resources tax, it's not enough to support deepwater oil and gas development, and need the assistance of other policies. For example, when we decrease resources tax by half, if we increase the tax threshold for special gain levy by 15 dollars per barrel, contractors' net present value will rise to 1.176 billion dollars, at the same time; IRR will increase to $12.52 \%$, and contractors' capacity to earn profit and conquer risks will be obviously improved.

\section{Conclusions}

South China Sea, especially in deepwater district, is rich in oil and gas resources. But the level of development is hindered by the limit of technology and fund. It's urgent to improve the ability of deepwater resources development, try hard to propel the development of deepwater oil and gas 
resources and make full use of deepwater oil and gas resources in South China Sea, especially those resources in controversial districts. With the features of high investment, high technology and high risks, deepwater oil and gas exploration need governments' support in finance and taxation clauses. At present, our country only provides preference policy for exploration over 300 meters under the sea with decrease of resources tax by $30 \%$. But this kind of preference policy cannot match the phase of deepwater oil and gas exploration in our country. While special gain levy which is related to oil price and aims at cost oil as well as profit oil, cannot tell apart the development cost of deep sea and shallow water, as well as land. Under the circumstance, in order to propel the development of offshore oil industry and be the power of sea, we should not only improve our equipment, but also perfect the finance and taxation system.

Based on current finance and taxation policies of deepwater oil and gas development in our country, taking the uncertainty of oil price and production cost into consideration, we can figure out that levying special gain levy on profit oil and cancelling Chinese share oil motivate the most for contractors, and it is of greatest possibility to realize the drawback of VAT by decreasing income tax to $15 \%$ and raising the tax threshold of special gain levy by 15 dollars per barrel. In addition, various kinds of preferential policies also contribute to the extension of foreign cooperation strategies and development of deepwater oil and gas resources. But it still remains to notice that it's a systematic and complex project to perfect related finance and taxation policies on exploration and development of deepwater oil and gas resources, we should propel it steadily and gradually perfect it. When we try to motivate contractors and CNOOC, at the same time, we should also protect our country's interests.

\section{Acknowledgement}

The authors are grateful for financial support from National Science and Technology Major Project (GN:2011ZX05030-006-04).

\section{References}

1. Wang Zhen, Chen Chuanying, Zhao Lin. Current Status and Challenges of Global Deepwater Oil and Gas Resources Exploration and Development[J], China and Foreign Energy Resources, 2010(01):46-49.

2. The US Bureau of Ocean Energy Management[OL].http://www.boem.gov/.

3. Hao H, Kaiser M. Modeling China's Offshore Production Sharing Contracts Using Meta Analysis[J]. Petroleum Science, 2010(02):283-288.

4. Schwartz E S. The Stochastic Behavior of Commodity Prices: Implications for Valuation and Hedging [J]. The Journal of Finance, 1997, 52(3):923-973.

5. Wang Dongjin, Li Xiusheng, Liu Mingming. Analysis on Economic Efficiency of International Petroleum Contracts Pattern Based on Random Process of Petroleum Price[J]. Acta Petrolei Sinica, 2012(03): 513-518.

6. Liu M M, Wang Z, Zhao L, et al. Production Sharing Contract: An Analysis Based on an Oil Price Stochastic Process[J]. Petroleum Science, 2012(03):408-415.

7. Pindyck R S. The Long-run Evolution of Energy Price[J]. The Energy Journal, 1999, 20(2):1-27.

8. Dixit A K, Pindyck R S. Investment under Uncertainty [M]. Princeton: Princeton University Press, 1994.

9. Zhang Hongliang, Wang Qiwen. Methods of Sample Size in Investment Project Risks Stimulation Analysis [J]. Theories and Practice of Systems Engineering, 2004(2):14-18. 